\title{
Research on the Mainstream Media Presentation of AIDS in the Framework of the Theory
}

\author{
Gao Delong; Wang Li* \\ University of Electronic Science and technology of China \\ School of politics and public administration, \\ Sichuan Chengdu
}

\begin{abstract}
In the area of health, AIDS has become an important problem that the whole society faces and the mass media should shoulder the social responsibility of disseminating health information. In this paper, let we take the mainstream media "People's Daily" as an example. With AIDS-related reports as the object of study, we found how the mainstream media in China reported on AIDS in the framework of the theory. The study found that the mainstream of AIDS in the media showed the following characteristics: the outbreak of the epidemic and the concern of the imbalance; concerns about the political color of AIDS; professional health reports and humanistic care disorders; AIDS sufferers "lost"; stealth discrimination.
\end{abstract}

Keywords-Health communication; "People's Daily"; AIDS; Media Presentation

\section{INTRODUCTION}

The mass media has the function of spreading health knowledge and it is also an important source of information for the public to understand AIDS information. From the perspective of mass communication, health communication plays an important role in disease prevention and health advocacy activities. Health communication is a social process that uses public media to maintain and promote health [1]. In the mainstream media in China, the serious and professional dissemination of content on the people's ideological awareness and action have an impact [2], mainstream media coverage of the number of topics for AIDS affects public awareness of AIDS. AIDS health research and scientific communication research has also become an important research topic in the field of journalism and communication. Some scholars have studied the news reports on AIDS discrimination from the media perspective to arouse the perceived bias and the predictive effect of this perceptual bias on safe behavior [3]. Some scholars have found that television, newspapers and networks are different in professional dimensions because of their media special effects and operating mechanism differences in the AIDS-related reports [4]. This paper analyzes the reports of the People's Daily on how to carry out AIDS issues in the long term.

Humanities and Social Sciences Fund of Ministry of Education "Research on Scientific Information Communication and Crisis

Communication from the Perspective of Risk Management" (16YJC860018);

Sichuan Provincial Social Science Key Research Base Project "Public Risk Awareness and Government Risk Prevention and Control in Scientific Issues Dissemination "(SR16A03)

\section{RESEARCH METHODS AND SAMPLE SELECTION}

Since 1974, Geoffman has introduced "framework analysis" into communication and framework theory has become an important theoretical method for analyzing media reports. Geffman argues that the framework refers to people's cognitive structure of the objective world. The induction, structure and interpretation of the real life experience are dependent on certain frameworks which enable people to locate, perceive, understand and summarize many specific information [5]. In this paper, we use content analysis and co-word analysis and select the authoritative, influential, clear source of the "People's Daily" as a case. The time is selected from January 1, 2000 to September 1, 2016 between the AIDS news and samples are from the "People's Daily Database" and "China's important newspaper full-text database". The news headline contains "AIDS", "Acquired Immunodeficiency Syndrome" "HIV", "AIDS" to retrieve and is supplemented by the theme of AIDS coverage. 282 effective reports are got by deleting duplicates and eliminating irrelevant reports.

According to the practice of news reports and the specific situation of AIDS reports, this article will build categories from the content of the topic, the number of reports, layout, news place and genre. AIDS coverage will be divided into: epidemic introduction, policy reports, conference reports, popular science knowledge, public welfare activities, scientific research activities, infection reports, advocacy prevention and treatment reports, and other nine categories. News is divided into: international news, domestic news and local news. Reported genre is divided into: news, newsletters, comments, in-depth reports, bulletins and other. Types of reports are divided into the graphic reports and text reported.

\section{SAMPLE ANALYSIS}

Through analyzing the "People's Daily" 282 AIDS related news reports, we can get the following situation:

1) Policies, meetings and advocacy prevention report most while epidemic and scientific research report moderate, popular science knowledge and infection and public welfare activities report less. The medical policy related to AIDS and 83 advocacy of AIDS prevention and treatment held at home and abroad on the theme of AIDS reported 40. In the construction of news content framework, "People's Daily" 
focuses on AIDS policy, meetings and other related reports, while it pays little attention to the disease and the daily life of infected people. And more from the world to introduce the epidemic situation in which developing countries, especially African countries, the frequency of the emergence is of a higher frequency and in the progress of AIDS research progress in developed countries accounted for a higher proportion of scientific research. In the report of China's scientific research activities, "Chinese medicine" is of high frequency and the contents of the report are strict the term "traditional Chinese medicine" has become more frequent in the coverage of scientific research activities in China. The report highlights the scientific nature of Chinese medicine in the prevention and treatment of HIV/AIDS. The first report is a paper entitled " traditional Chinese medicine will be involved in HIV/AIDS prevention and treatment" and traditional Chinese medicine for HIV/AIDS prevention and control are all positive report.

2) From 2003 to 2005, the number of articles was large, and the other years were relatively gentle. (Figure 1) Reports of AIDS reported from 2003 to 2005 are the maximum number of article, there are several reasons: First, the SARS outbreak in 2003 makes all kinds of infectious diseases, including AIDS awareness; second, the spread of health has become an important point of focus for the mass media. Third, the government's policy on infectious disease is closely related. But for a long period of time to see "People's Daily" reported for AIDS similar to the "holiday effect" phenomenon, which is due to December 1 each year, "World AIDS Day" before and after, including the "People's Daily" Many media appeared to report the phenomenon of intensive, but in the usual report has diluted the AIDS-related "issues" of the report.

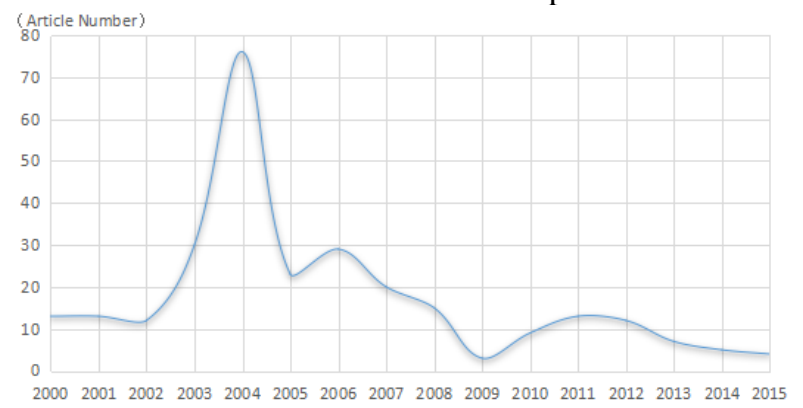

Fig. 1. "People's Daily" on AIDS report number

3) From report genre, the short message classes reported the highest proportion, communication, in-depth reporting is less, and at least $90 \%$ of the reported for text, picture and text report accounted for less than 10\%. The People's Daily used a variety of different genres for AIDS coverage, but the weight of all kinds of bodies was unbalanced. Most of the coverage of the AIDS epidemic is lacking in depth. The report and in-depth coverage were 31 , with a report from the third person saying that there were very few self-reported content of HIV-positive people. AIDS communication, reviews and in-depth reporting narrative has three kinds of situations: First, HIV/AIDS infection and brave resistance or the struggle for AIDS prevention and treatment for research of medical scientific research personnel; Second, the concern of the leaders of the party and government about the care and care of the AIDS patients, and the care and understanding of the people of all walks of life. Third, the attitude of the state and the whole society on the positive prevention and control of HIV/AIDS.

4) From the source of information, domestic news and local news account for about 65\%, international news accounts for about $30 \%$, and others are information about AIDS. For a quite long period, the People's Daily reports of AIDS still focus on the domestic situation, at the same time reports about HIV/AIDS epidemic situation abroad, as well as the scientific reports and other relevant information also occupies a considerable proportion. In the coverage section, the report on AIDS was published in section 3, 5, 6, 7 and 11, accounting for about 60 percent. On the front page and in the main story, there are fewer copies, and the country's leading leaders have a high frequency of visiting and writing articles on the front page or on the front page of AIDS patients.

5) There is a phenomenon in which the author of the article about AIDS reports has repeatedly published articles. (Table 1) This article defines these authors as "author groups". By the word analysis of word frequency analysis, the People's Daily reports on AIDS from author groups accounted for $30 \%$ $40 \%$ of the total sample. Bai jianfeng, the editor of the People's Daily economic society, wrote the most AIDS articles in 34 articles. The more stable "author group" is helpful in making AIDS coverage consistent reporting and forms a reporting authority on the value orientation of AIDS. But it also limits the diversity of information about HIV/AIDS, which is bad for AIDS patients, researchers, medical staff and other self-reported expressions of AIDS.

TABLE I HIGH-FREQUENCY AUTHOR

\begin{tabular}{|c|c|}
\hline Author & Number \\
\hline Bai Jianfeng & 34 \\
\hline Wang Shujun & 19 \\
\hline Wang Junping & 11 \\
\hline Ding wei & 9 \\
\hline He Hongze & 7 \\
\hline Zhou Dehao & 6 \\
\hline Wang Minghao & 6 \\
\hline Li Xinfeng & 5 \\
\hline
\end{tabular}

\section{THE DISCOURSE SYSTEM IN THE REPORT}

Through the analysis of the common words for all samples (table 2, the partial data), it is concluded that the People's Daily, title presents four words package when reporting on HIV/AIDS: First, prevention is the main framework on HIV/AIDS report. Over a longer period of time, the People's Daily is committed to advocacy on HIV/AIDS prevention and 
control, "prevention", "AIDS", "prevention" and "containment", "control" and other words in HIV/AIDS report rate is higher, and advocate "action", including international cooperation. It also highlights the importance of "action" within the framework of the prevention and control of the media reports. Second, the severity of the epidemic is the focus of AIDS-related reports. In the content focused on the report of the AIDS epidemic, including the situation at home and abroad, the high incidence of AIDS and the new situation for the AIDS epidemic reported. For example, the gay community the trend of the spread of HIV/AIDS. In the course of specific reports, the situation of the epidemic is introduced in the form of Numbers and proportions. Third, research continues, the government is working hard. In the treatment of AIDS treatment related to the "positive" attitude, both at home and abroad for AIDS research are often mentioned, which emphasizes the traditional Chinese medicine on the positive role of AIDS treatment. In AIDS prevention and control as well as policy emphasizes the important role of the government, including the "central", "the state council", "government", "society", "love" and "rescue", "warm" is the political reporting framework of AIDS. Fourth, there is a certain bias in favor of a neutral or positive stance on AIDS coverage. In the case of AIDS, for example, developing countries have become the main actors in the media, especially in African countries such as South Africa. Domestic report "Henan" is highly correlated with AIDS media present place. In addition, HIV/AIDS are more associated with orphans, poverty and education, etc.

TABLE II WEIGHTS OF HIGH FREQUENCY WORDS

\begin{tabular}{|l|c|c|c|c|c|}
\hline Keyword & Frequency & Weight & Keyword & Frequency & Weight \\
\hline AIDS & 217 & 1 & HIV & 7 & 0.6552 \\
\hline $\begin{array}{l}\text { Prevention } \\
\text { and control }\end{array}$ & 63 & 0.8389 & Henan & 10 & 0.6501 \\
\hline Patient & 21 & 0.7213 & Containment & 8 & 0.6389 \\
\hline Anti AIDS & 10 & 0.702 & United Nations & 8 & 0.6299 \\
\hline Prevention & 16 & 0.6938 & Plague & 7 & 0.614 \\
\hline Vaccine & 11 & 0.6741 & $\begin{array}{c}\text { Chaditional } \\
\text { Chinese }\end{array}$ & 6 & 0.6137 \\
\hline Treatment & 13 & 0.664 & Africa & 6 & 0.6105 \\
\hline Action & 13 & 0.6671 & Fight & 6 & 0.6102 \\
\hline Spread & 10 & 0.6603 & Orphans & 6 & 0.6092 \\
\hline
\end{tabular}

\section{CONCLUSION AND DISCUSSION}

From the report on the leading framework, the "People's Daily" has been committed to the report on AIDS prevention and control and achieved some coverage. But there are five aspects of the problem: the introduction of the epidemic and the concern of the imbalance; the political color of AIDS; professional health reports and humanistic care disorders; AIDS sufferers "lost"; stealth discrimination.

The data of the epidemic shows the neglect of the course of the infected person. The introduction of the epidemic is "People's Daily" on AIDS-related reports of important content, whether it is the international epidemic or domestic reports of the epidemic, which are cited authoritative sources of information, reflecting the rigorous reporting attitude. But the specific content of the report to digital, proportion, numerical and other macro data show weakened the public for AIDS, especially AIDS, the specific course of infection, easy to produce a "sense of distance." The mass media should provide a platform for discussion on HIV-related issues to achieve consensus among the AIDS community, the public, the government and the media on the solution to this problem. In the AIDS news genre, the proportion of people communication, event communication and in-depth reporting should be increased and the coverage should also be related to the coverage of HIV / AIDS knowledge, public welfare activities and the fight against the disease. In the report on the issue of AIDS should be arranged on the basis of "World AIDS Day" and other "holiday effect" in the report accurately guide the public to form a rational treatment of AIDS.

The government's anti-AIDS related meetings and policy reports are too much. Although it constructs the AIDS political framework, it also highlights the role of government. And it makes the AIDS itself and the main body of infected people weakened. There are few reports on the implementation of HIV-related policies and the collection of free medicines, condom distribution and the implementation of AIDS policy should be a practical issue. In addition, the development of AIDS public welfare activities and the social status of AIDS groups should also be reflected in the mass media reports. Mainstream media should be "ground" on the AIDS political framework report, with a variety of perspective to report the relevant policies.

From the perspective of health communication, AIDS-related reports of information sources should come from more scientific research workers, health care workers, people living with HIV and volunteers. Diversified sources of information and information channels are conducive to more 
fully and correctly guide the public's attitude towards HIV / AIDS. A small number of journalists have written a considerable number of articles on AIDS, making the media in the AIDS reported on the habit of fixed coverage, which is not conducive to a variety of media presentations. From the perspective of health communication, AIDS-related reports of information sources should come from more scientific research workers, health care workers, people living with HIV and volunteers. Diversified sources of information and information channels are conducive to more fully and correctly guide the public's attitude towards HIV / AIDS. A small number of journalists have written a considerable number of articles on AIDS, making the media in the AIDS reported on the habit of fixed coverage, which is not conducive to a variety of media presentations. AIDS in the field of medical research has its own words to express, media journalists should strengthen the professional knowledge of the spread of AIDS and the incidence of a comprehensive understanding of the scientific conduct of AIDS related reports. While we should continue to focus on AIDS-related scientific research and the situation of the epidemic, such as the evolution of AIDS transmission channels, changes in infected groups and so on. In the process of writing and reporting, we should avoid the "demons", "world-class plague" and other words with fear of voices and reflect the media's humanistic care to avoid discrimination. We should pay attention to the voice of infected groups. On the one hand, we can continue to focus on the process of infection with the diseases. On the one hand, we should deepen understanding of the needs of infected groups to avoid mixing AIDS and poverty, education and other issues.

\section{REFERENCES}

[1] Hong Junhao. New trends in communication [M]. Beijing: Tsinghua University Press, 2014. 266

[2] Qiang Yue new, Xia Zhongmin. Current mainstream media influence in China's research and analysis [J]. News reporter, 2016, (11): 35-43.

[3] Qiu Hongfeng, Peng Lulu. Collectivism culture and AIDS discrimination reported third effect [J] .In the press, 2016, (21): 11-20.

[4] Liu Quan, Jane D. Brown, ZHAO Xin-shu.Study on the professional dimension of AIDS coverage in different media in mainland China 2009 World AIDS Day As a sample [J]. Journalism and Communication Studies, 2012, 02: 28-34 + 110 .

[5] Guo Qingguang. Communication Course [M]. Beijing: Renmin University of China Press, 2012. 208-213. 